\title{
Influence of Skewed Squirrel Cage Rotor with Intermediate Ring on Magnetic Field of Air Gap in Induction Machine
}

\author{
Zelmira Ferkova $^{1}$, Vladimir Kindl ${ }^{2}$ \\ ${ }^{I}$ Faculty of Electrical Engineering and Informatics Technical University of Kosice, \\ Kosice, Slovakia \\ ${ }^{2}$ Faculty of Electrical Engineering/RICE, University of West Bohemia, \\ Pilsen, Czech Republic \\ zelmira.ferkova@tuke.sk
}

\begin{abstract}
The article compares the flux density spectrum in air gap of squirrel-cage induction machine with different rotor geometries. The skewed squirrel cage with an intermediate ring and ordinary skewed squirrel cage are compared to the straight bars rotor using the finite element method. The novelty lies in a deep investigation in issues relating to rotor cage with an intermediate ring.
\end{abstract}

Index Terms-Induction machine; intermediate ring; space harmonics; skewed cage.

\section{INTRODUCTION}

The smooth operation of an induction machine is under the influence of the slots geometry along with the winding distribution and the iron core saturation. These features strongly predefine the spectrum of the air gap magnetic flux density [1]-[4]. It includes many harmonic components (space harmonics) producing parasitic torques, additional losses and acoustic noise even under common operational states [5]-[10]. Reduction of the high frequency components of the spectrum is therefore an important issue that must be considered prior to designing the machine.

Either a properly designed winding or carefully constructed rotor may partially reduce space harmonics present in the air gap flux density spectrum. While the winding design affects mainly the lower harmonic components (phase belt harmonics), it has almost no impact on harmonics caused by slotting of the lamination. These harmonic components may be effectively suppressed by skewing the rotor slots [11]-[16] which on contrary reduces also the average torque and generates extra rotor side pull. In case of skewed rotor, one side of the rotor bar is axially shifted from its second side by a fraction of slot pitch. The flux along the rotor axis therefore significantly varies (skew leakage flux). The changing flux linkage induces a different

Manuscript received 17 December, 2015; accepted 11 June, 2016.

This research has been supported by the Ministry of Education, Youth and Sports of the Czech Republic under the RICE - New Technologies and Concepts for Smart Industrial Systems, project No. LO1607., TAČR project no. TE02000103 Centre for Intelligent Drives and Machines (CIDAM) and by the grant of Slovak Science Grant Agency No. VEGA $1 / 0121 / 15$. voltage at any point of the bar along its length. This generates current flowing in the rotor bars and peripherally through the laminations. These currents are called inter-bar or cross currents. An additionally placed intermediate ring [17] provides closed current path leading small balancing currents. Hence, the cross currents through the laminations are much lower. The intermediate ring divides the rotor into two separated cages with mutual tangential shift corresponding to the global angle of skew. This particular arrangement considerably compensates both the side pull and skew leakage flux [1], [2].

Main issues of skew effects on squirrel cage induction machine have been already discussed at global scale in common literature [11]-[16] but a discussion on skewed rotor with an intermediate ring remains absent yet. This article contributes mainly with the discussion on frequency spectrum of air gap flux density of such machines. The comparison of three different rotor types (skewed rotor with intermediate ring, skewed rotor, straight bars rotor) has been made to support all conclusions.

\section{BASIC ANALYSIS OF THE MACHINE STUDIED}

The studied machine is an ordinary industrial four-pole $(2 p=4)$ induction machine utilizing aluminium single-cage with deep rotor bars to meet the high rotor locked torque with low starting current and low rated slip. The cage is composed of two sections of skewed rotor bars interconnected via an intermediate ring. As seen in Fig. 1, it is organized in "wide arrow" configuration.

The stator winding is placed in only one layer and is wound from concentric coils. The lamination features $Q_{1}=$ 48 slots on the stator and $Q_{2}=36$ slots on the rotor. Rated parameters of the machine are presented in Table I.

Since the windings are arranged in only one layer, no coil chording is possible. The stator therefore produces magnetic field in the air gap consisting of a sum of odd harmonic components [1], [2]

$$
v=2 m c \pm 1
$$

They are traveling in both directions -with and against to 
the fundamental wave (according to operator " \pm "). Here, $m$ is a number of stator phases and $c$ is an integer $(c=1,2$, 3 ...). Besides (1) the spectrum includes also multiples of the $3^{\text {rd }}$ harmonic components caused by core saturation.

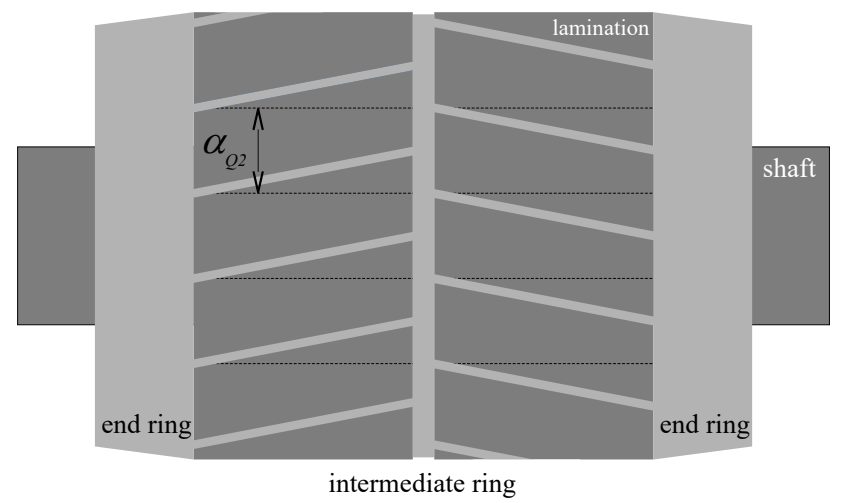

Fig. 1. The rotor construction of the analysed induction machine.

TABLE I. RATED PARAMETERS OF ANALYSED MACHINE.

\begin{tabular}{|c|c|c|}
\hline \multicolumn{3}{|c|}{ SIEMENS 1LA7 163-4AA10 } \\
\hline Parameter & Value & Unit \\
\hline Rated power $P_{r}$ & 11 & $\mathrm{~kW}$ \\
\hline Terminal voltage $U_{r}$ & $\mathrm{Y} 400 / \Delta 230$ & $\mathrm{~V}$ \\
\hline Rated current $I_{r}$ & 21.5 & A \\
\hline Rated torque $T_{r}$ & 72 & $\mathrm{~N} \cdot \mathrm{m}$ \\
\hline Rated speed $n_{r}$ & 1467 & $\mathrm{r} / \mathrm{min}$ \\
\hline Rated power factor $\cos \left(\varphi_{r}\right)$ & 0.84 & - \\
\hline Rated efficiency $\eta_{r}$ & 88.5 & $\%$ \\
\hline
\end{tabular}

The air gap magneto-motive force corresponding to the particular harmonic component may be given as

$$
F_{\delta v}=\frac{m N_{S} I \sqrt{2}}{\pi p} \frac{k_{w v}}{v}
$$

where, $I$ is the current flowing through $N_{S}$ winding turns and $k_{w v}$ is the winding factor (3)

$$
k_{w v}=\sin \left(v \frac{\pi \beta}{2}\right) \frac{\sin \left(v \frac{\pi}{6}\right)}{q \times \sin \left(v \frac{\pi}{6 q}\right)} .
$$

In (3), the parameter $\beta$ represents the coil's chording defined as a ratio of chorded coil number of slots and full pitched coil number of slots. Parameter $q$ is the number of slots per pole and phase

$$
q=\frac{Q_{1}}{2 p m}
$$

Most of harmonic components predicted in (1) lower their magnitudes very quickly with rising order and falling winding factor. The only exception are harmonics caused by lamination slotting classified as step harmonics (5)

$$
v_{\text {step }}=c \frac{Q_{1,2}}{p} \pm 1 \text {. }
$$

They all have the winding factor equal to the winding factor calculated for fundamental wave.

\section{FE ANALYSES OF VARIOUS ROTOR CONSTRUCTIONS}

In order to evaluate the influence of intermediate ring on machine's operation, three different rotor constructions are analysed and compared using the finite element method. The first one, a straight bars rotor (see Fig. 2) is considered as a benchmark for other rotor types. Secondly, the ordinary skewed rotor (see Fig. 5) is analysed. And thirdly, effects of skewed rotor with an intermediate ring (see Fig. 1) with tangentially shifted "arrow shaped" bars are investigated.

The fully transient FE analyses is used for electromagnetic field calculations. Three dimensional models taking into account the rotor speed and inherent nonlinearities are prepared for each study case. The rotor skewing is therefore considered by rotor geometry.

\section{A. Straight Bars Rotor}

As obvious from (5), the spectrum of the air gap magnetic field includes besides the fundamental wave also other (step harmonics) components with an identical value of the winding factor [1], [2].

Their amplitudes are therefore inversely proportional to their order and have relatively strong influence even in case of high considered harmonic order.

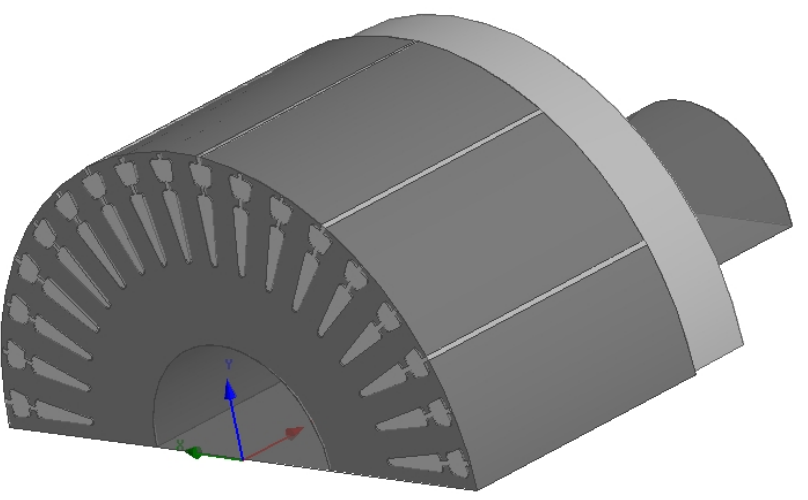

Fig. 2. The model of the studied straight bars rotor.

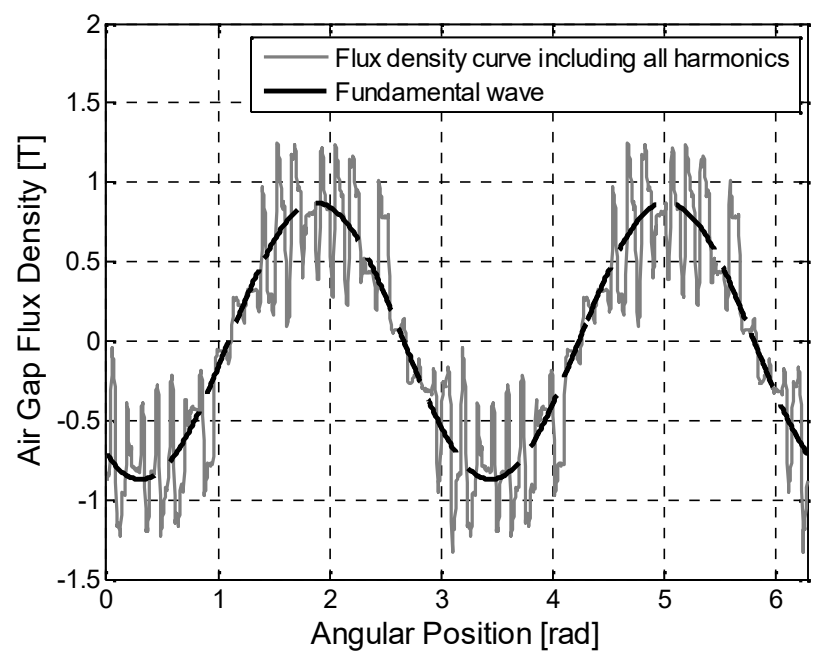

Fig. 3. The rated torque air gap flux density-straight bars rotor.

According to (5), all magnitudes of orders $c Q_{1}+1$ subtract from their respective slot harmonics no matter how 
the winding is chorded. The same rule holds for orders $c Q_{1}-$ 1 , but they add to the respective slot harmonics. The interaction between the step and the rotor slot harmonics is similar. The model (Fig. 2) uses the advantage of quarter-symmetry to reduce the computation time. The stator coils are modelled as single wires with hypothetical number of turns.

Figure 3 illustrates the normal component of rated-torque air gap magnetic field in dependency on angular position $\left(T_{r}=72 \mathrm{~N} \cdot \mathrm{m}\right.$ and speed $\left.n_{r}=1466 \mathrm{r} / \mathrm{min}\right)$. The curve is derived from the centre of the air gap in the middle of the rotor length. The corresponding frequency spectrum may be seen in Fig. 4. Because the single-layer winding is wound from full-pitched coils, the $5^{\text {th }}$ and the $7^{\text {th }}$ harmonics became relatively strong. The $11^{\text {th }}$ and $13^{\text {th }}$ orders are both strong because of worse distributed windings.

These (phase belt) harmonics would be furthermore reduced either with using higher $q$ or transfiguration the winding into its chorded double-layer form.

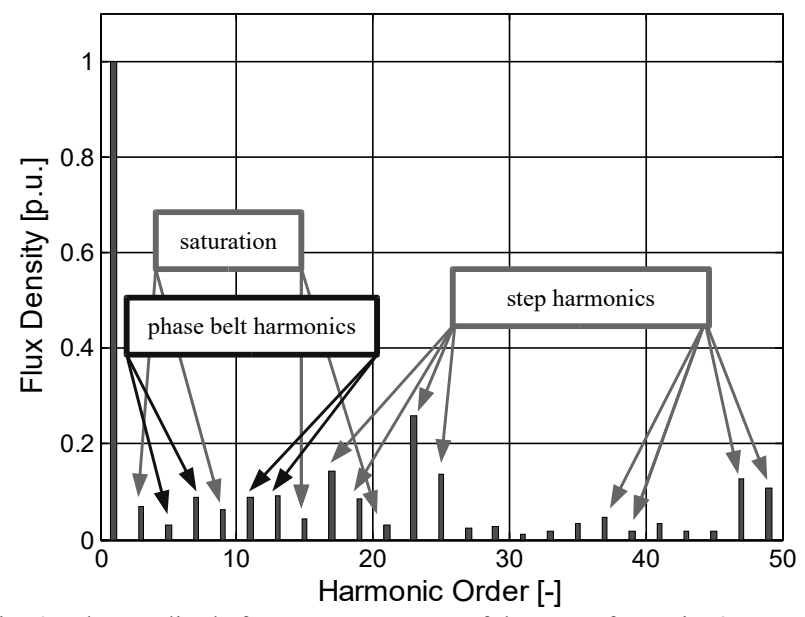

Fig. 4. The amplitude frequency spectrum of the curve from Fig. 3.

As seen in Fig. 4, the step harmonics play a disturbing role in machine's operation (produce significant asynchronous torques) especially in case of straight bars rotor. Harmonic components obtained from subsequent spectral analyses are all referred to the fundamental wave of the straight rotor machine (seen in Fig. 4).

\section{B. Skewed Rotor}

While the straight rotor cage provides the operation with amount of disruptive effects (cogging torque, torque ripple, vibrations and noise) caused by unsuppressed air gap harmonics, the skewed rotor cage may reduce them significantly. But to the contrary it brings uneven field distribution along the axial direction leading to the greater core saturation, poorer efficiency and lower power factor due to cross currents. The voltage induced at any point of rotor bar skewed by angle

$$
\gamma=\frac{2 \pi p}{Q_{1}},
$$

is such that the phase shift at both sides of the bar is $v \gamma$. The resultant voltage is therefore given by numerical integration of all elementary voltages over the bar length and is $k_{s k w^{-}}$ times (7) lower than the voltage induced in straight bar.

$$
k_{s k w}=\frac{\sin \left(v \frac{\gamma}{2}\right)}{v \frac{\gamma}{2}} .
$$

The analysed skewed rotor model is illustrated in Fig. 5.

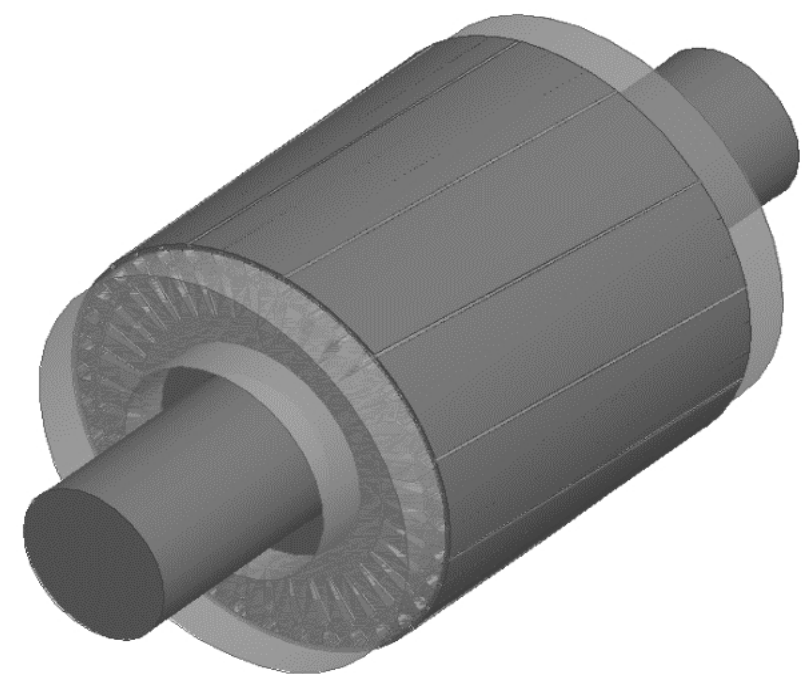

Fig. 5. The model of the studied rotor with skewed bars.

In order to get valid comparison between ordinary skewed and skewed rotor with the intermediate ring, the skewing is considered to be constant (equal to one stator slot pitch). The rotor skewing [1], [2] referred to the stator is as (7).

Figure 6 shows the influence of skewing on the resultant winding factor for a particular harmonic component. Dashed line with cross markers represents the plain winding factor obtained from (3). All step harmonics generated by the stator and the rotor slotting (5) are effectively suppressed due to rotor skewing represented by skewing factor introduced in (7) - plotted in dashed line with circle markers. The resultant winding factor considering the rotor skew is depicted in solid line with square markers.

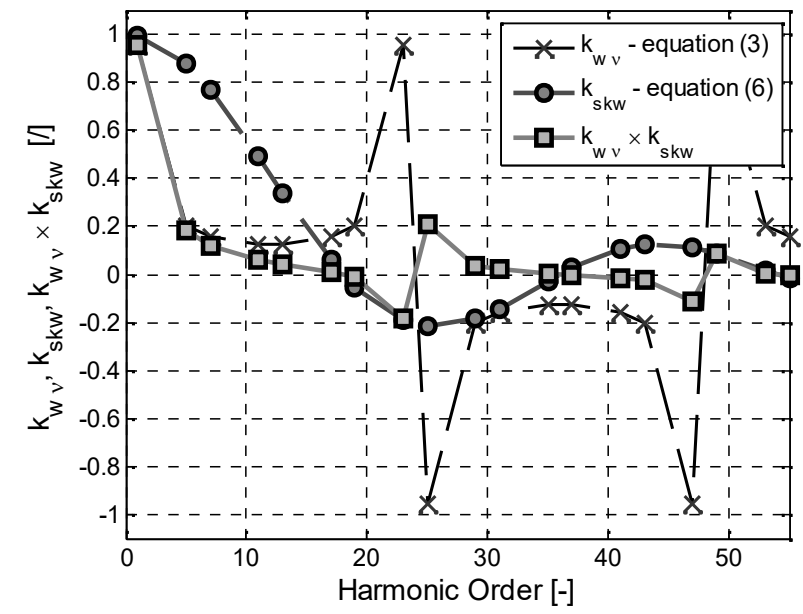

Fig. 6. The winding factor for particular harmonics considering straigth and skewed bars rotors.

The reduced spectrum of the air gap magnetic field generates smoother torque and makes the machine less noisy. The air gap flux density for the rated torque $\left(T_{r}=\right.$ 
$72 \mathrm{~N} \cdot \mathrm{m}$ and speed $n_{r}=1462 \mathrm{r} / \mathrm{min}$ ) is illustrated in Fig. 7.

The resulting frequency spectrum is shown in Fig. 8. As can be seen, rotor skewing introduces further harmonic components into the spectrum. In this case, every single integer harmonic forms the $0.5^{\text {th }}$ order sidebands to the same harmonic order present in the spectrum without the skewing.

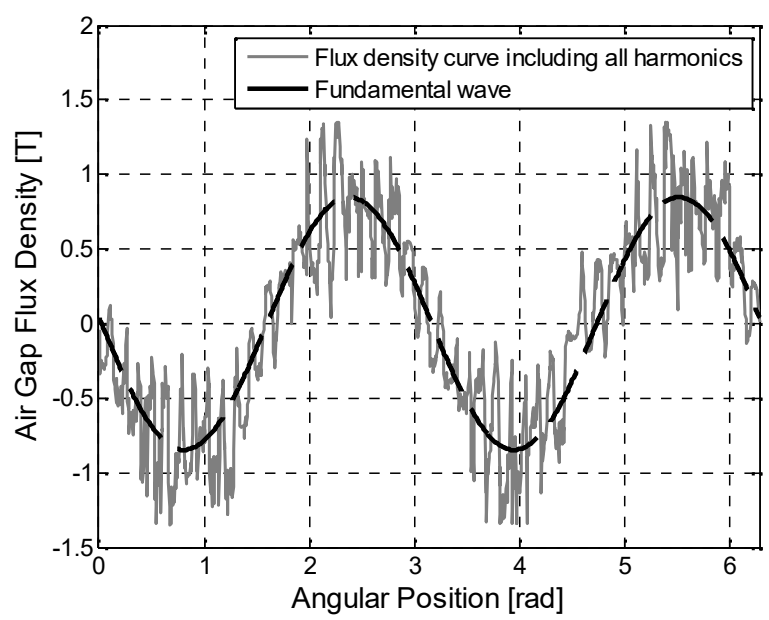

Fig. 7. The rated-torque air gap flux density-skewed bars rotor.

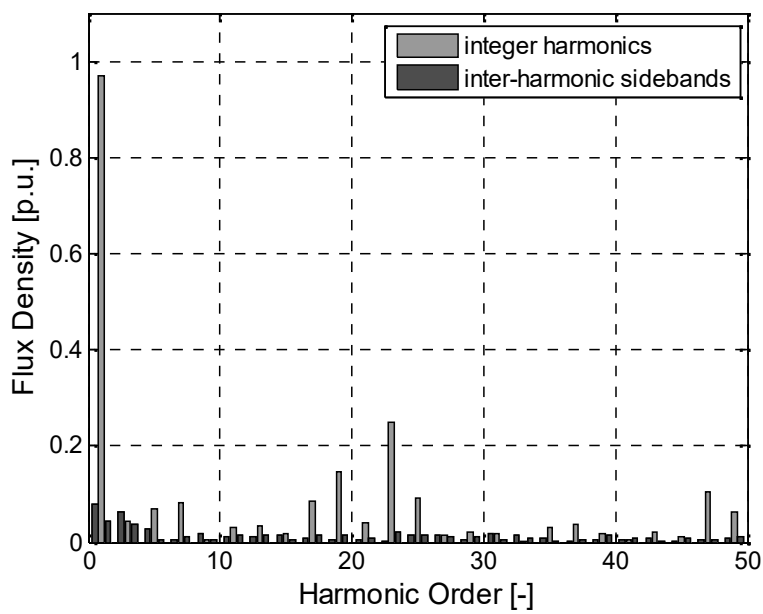

Fig. 8. The amplitude frequency spectrum of the curve from Fig. 7.

As predicted by (7), the fundamental wave has slightly lower magnitude than the fundamental wave calculated for straight bars rotor model. For the same considered load, this results in lower available torque and consequently higher slip (rotor loss). On the other hand, all the rotor step harmonics and higher multiples of the stator step harmonics are effectively suppressed.

\section{Skewed Rotor with Intermediate Ring}

While the skewed rotor with the intermediate ring (Fig. 9) provides almost identical operational benefits as described in the previous section, it brings some extra improvements in efficiency and service time of the bearings due to reduced cross currents and balanced side magnetic pull.

The air gap flux density calculated for rated-torque $\left(T_{r}=\right.$ $72 \mathrm{~N} \cdot \mathrm{m}$ and $n_{r}=1460 \mathrm{r} / \mathrm{min}$ ) investigated at the quarter and the half of the machine's length is plotted in Fig. 10.

The intermediate ring strongly decreases the flux density in the centre of the rotor length due to the large virtual air gap. This increases the magnetizing current and the power-factor is therefore slightly poorer than in case of a simply skewed rotor.

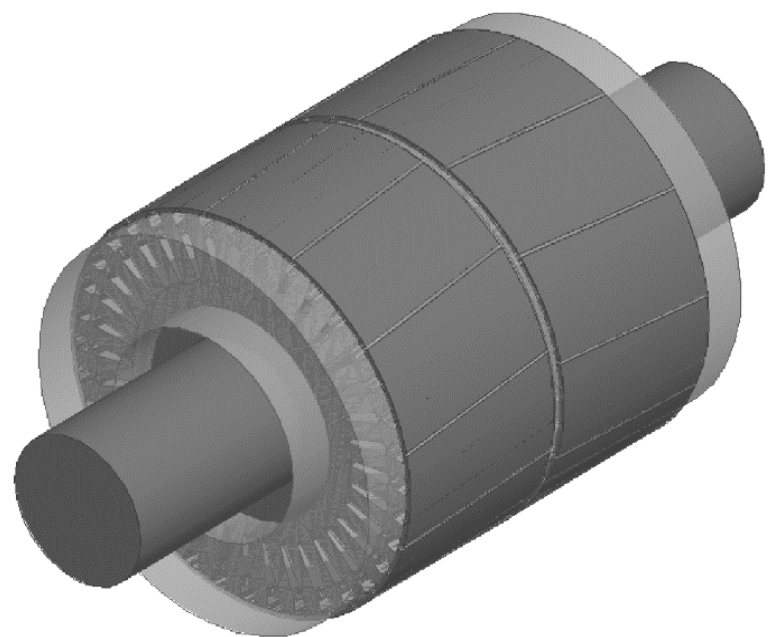

Fig. 9. The model of the studied rotor with skewed bars and intermediate ring.

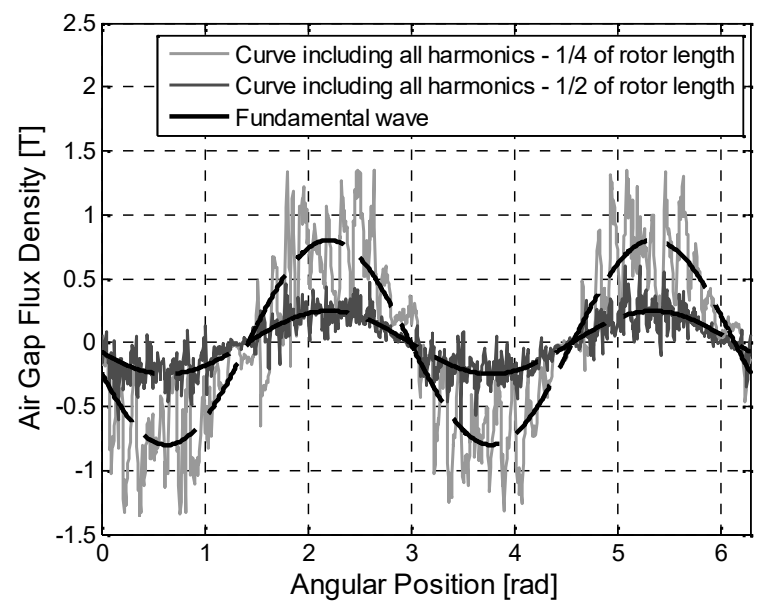

Fig. 10. The rated-torque air gap flux density for a skewed rotor with an intermediate ring.

On the other hand, it reduces the cross currents and consequently improves the efficiency. Since the frequency content of the air gap field above the intermediate ring can affect parasitic torques only a bit, it will be left undiscussed. Only the field outside close vicinity of the intermediate ring will be analysed.

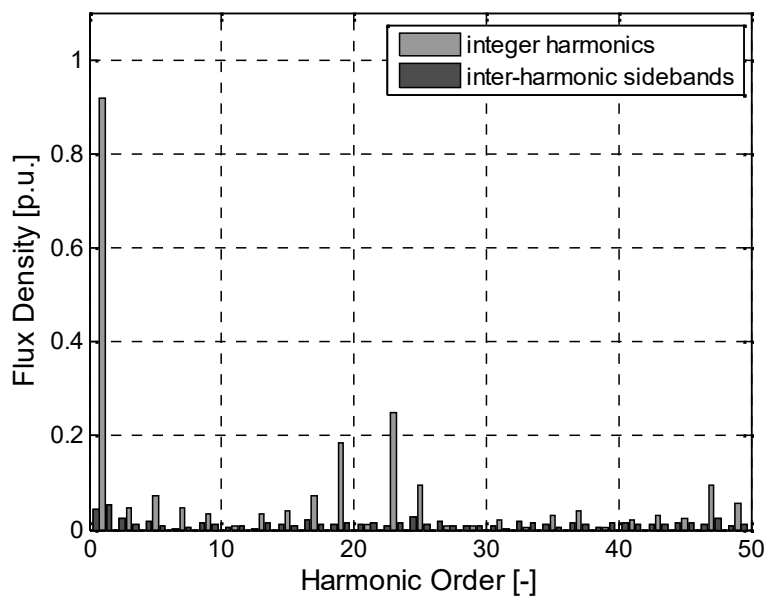

Fig. 11. The amplitude frequency spectrum of the curve from Fig. 10 (in $1 / 4$ of rotor length).

As seen in Fig. 11 and Fig. 4, with comparison to the 
straight bars rotor the "arrow rotor" type suppresses most of the inter-harmonics and makes the machine more silent. On the other hand, it brings almost no advantage compared to simply skewed rotor type. The air gap frequency contents for both skewed rotor types are almost identical. Numeric comparisons of the above discussed frequency spectrums are presented in Table II.

TABLE II. NUMERAL COMPARISON OF STUDIED ROTORS.

\begin{tabular}{|c|c|c|c|}
\hline $\begin{array}{c}\text { Harmonic } \\
\text { order }\end{array}$ & Straight & Skewed & $\begin{array}{c}\text { Harmonic Component with } \\
\text { intermediate } \\
\text { ring }\end{array}$ \\
\hline $1^{\text {st }}$ & 1 & 0.971 & 0.922 \\
\hline $5^{\text {th }}$ & 0.031 & 0.0727 & 0.073 \\
\hline $7^{\text {th }}$ & 0.087 & 0.081 & 0.045 \\
\hline $11^{\text {th }}$ & 0.089 & 0.031 & 0.008 \\
\hline $13^{\text {th }}$ & 0.091 & 0.034 & 0.032 \\
\hline $17^{\text {th }}$ & 0.142 & 0.084 & 0.071 \\
\hline $19^{\text {th }}$ & 0.086 & 0.148 & 0.184 \\
\hline $23^{\text {rd }}$ & 0.260 & 0.251 & 0.241 \\
\hline $25^{\text {th }}$ & 0.137 & 0.091 & 0.091 \\
\hline $35^{\text {th }}$ & 0.034 & 0.031 & 0.031 \\
\hline $37^{\text {th }}$ & 0.046 & 0.037 & 0.039 \\
\hline $47^{\text {th }}$ & 0.126 & 0.103 & 0.094 \\
\hline $49^{\text {th }}$ & 0.107 & 0.061 & 0.057 \\
\hline
\end{tabular}

The presented results introduce great coincidence with the above discussed theoretical expectations.

\section{CONCLUSIONS}

Harmonic content of the induction machine's air gap flux density strongly depends on geometry of the slotting, saturation, operation state and many other issues.

While considering the straight rotor bars the spectrum of the air gap field is relatively rich and produces significant disturbance by noise and unsuppressed parasitic torques. The situation differs in some qualitative matters in the case of modified rotor construction used.

The skewed rotor effectively reduces some specific integer harmonic orders (including fundamental wave), but to the contrary, it adds to them the $0.5^{\text {th }}$ order sidebands caused by uneven field distribution along the axial direction. This results in greater local core saturation, worse efficiency and lower power factor due to the cross currents. Moreover, there is some uncompensated side pull due to one-direction skewing and lower speed for a given loading torque.

The additional intermediate ring introduces larger virtual air gap in the centre of the rotor length leading to the working flux drop and lower overload capacity. The resulting higher magnetizing current makes the power-factor slightly worse than it is in the case of simply skewed rotor, but with reduction of cross currents the rotor improves the efficiency. From the frequency spectrum shown in Fig. 11 it is clear that while the all inter-harmonics are suppressed largely, the integer orders are reduced only slightly. The speed for a given loading torque seems to be somewhat lower than in the previous case. All presented results are representative for common industrial induction machines with die-cast rotor cage.

\section{REFERENCES}

[1] B. Heller, V. Hamata, Harmonic field effects in induction machines. Elsevier: Amsterdam, 1977.

[2] I. Boldea, S. A. Nasar, The induction machine handbook. CRC Press: Boca Raton, 2002.

[3] L. Schreier, J. Bendl, M. Chomat, "Influence of space harmonics on properties of six-phase induction machine - Part I. analysis", in XIX Int. Conf. Electrical Machines (ICEM), 2010, pp. 1-6. [Online]. Available: http://dx.doi.org/10.1109/ICELMACH.2010.5608155

[4] A. Tessarolo, M. Mezzarobba, A. Contin, "A stator winding design with unequally-sized coils for adjusting air-gap space harmonic content of induction machines", XIX Int. Conf. Electrical Machines (ICEM), Rome, 2010, pp. 1-7. [Online]. Available: http://dx.doi.org/10.1109/ICELMACH.2010.5608286

[5] V. Kindl, M. Hajzman, "Identification of harmful time harmonic interactions in a high power squirrel-cage traction machine", Applied Mathematical Modeling, vol. 38, no. 24, pp. 6153-6169, 2014. [Online]. Available: http://dx.doi.org/10.1016/j.apm.2014.05.013

[6] L. Golebiowski, D. Mazur, "The effect of strong parasitic synchronous and asynchronous torques in induction machine with rotor eccentricity", 10th Mediterranean Electrotechnical Conf. (MELECON 2000), 2000, pp. 982-985. [Online]. Available: http://dx.doi.org/10.1109/MELCON.2000.879697

[7] A. Stening, C. Sadarangani, "Reduction of synchronous torques in induction machines using asymmetrical rotor slots", in 15th Int. Conf. Electrical Machines and Systems (ICEMS 2012), 2012, pp. 1-6.

[8] D. Dorrell, L. Frosini, M. Bottani, G. Galbiati, "Calculation of starting torque in skewed-rotor cage induction motor with broken bar and rotor eccentricity using hybrid analytical/finite element analysis technique", IEEE Energy Conversion Congress and Exposition, (ECCE 2009), 2009, pp. 3970-3977. [Online]. Available: http://dx.doi.org/10.1109/ECCE.2009.5316245

[9] Houquan Zhu, Guihou Zhou, Jin Chen, Hailong Liu, "Analysis and study of skewed slot tooth distance on low electromagnetic noise of three-phase induction motor with squirrel cage rotor", Sixth Int. Conf. Electromagnetic Field Problems and Applications (ICEF), 2012, pp. 1-4. [Online]. Available: http://dx.doi.org/10.1109/ ICEF.2012.6310362

[10] Hyun Rok Cha, Cheol Ho Yun, Tae Uk Jung, Hyung Mo Kim, Jeong Cheol Kim, Seung Hun Baek, Kwang-Heon Kim, "A control of the MMF space harmonic parasitic torques in the concentrated winding AC machine using skew angle optimization", 32nd Annual Conf. IEEE Industrial Electronics, (IECON 2006), 2006, pp. 1018-1022. [Online]. Available: http://dx.doi.org/10.1109/IECON.2006.348059

[11] D. G. Dorrell, P. J. Holik, C. B. Rasmussen, "Analysis and effects of inter-bar current and skew on a long skewed-rotor induction motor for pump applications", IEEE Trans. Magnetics, vol. 43, no. 6, pp. 2534-2536, 2007. [Online]. Available: http://dx.doi.org/10.1109/ TMAG.2007.892537

[12] W. N. Fu, S. L. Ho, H. C. Wong, "Design and analysis of practical induction motors", IEEE Trans. Magnetics, vol. 37, no. 5, pp. 3663 3667, 2001. [Online]. Available: http://dx.doi.org/10.1109/20.952685

[13] P. Wendling, A. Perregaux, A. Akabar, Y. LeFloch, P. Lombard, L. Sadi-Haddad, "Two techniques for modeling an induction motor with skewed slots with a time-stepping 2D-3D finite element method", IEEE Electric Ship Technologies Symposium, 2005, pp. 463-467. [Online]. Available: http://dx.doi.org/10.1109/ESTS 2005.1524716

[14] Byung-Il Kown, Byung-taek Kim, Cha-Seung Jun, Seung-Chan Park, "Analysis of axially non-uniform loss distribution in 3-phase induction motor considering skew effect", IEEE Trans. Magnetics, vol. 35, no. 3, pp. 1298-1301, 1999. [Online]. Available: http://dx.doi.org/10.1109/20.767189

[15] T. Yamaguchi, Y. Kawase, S. Sano, "3-D finite-element analysis of skewed squirrel-cage induction motor", IEEE Trans. Magnetics, vol. 40, no. 2, pp. 969-972, 2004. [Online]. Available: http://dx.doi.org/10.1109/TMAG.2004.824897

[16] P. Smolskas, M. Zmuida, "Analysing Torque-slip Characteristic of a Small Power Induction Motor Operating under Geophysical Conditions", Elektronika ir Elektrotechnika, vol. 22, no. 1, pp. 1418, $2014 . \quad$ [Online]. http://dx.doi.org/10.5755/j01.eee.22.1.7065

[17] L. Alger Philip, "Intermediate ring squirrel cage rotor", US Patent 2,944,171, issued June 5, 1960. 